\title{
Specific spectroscopic features of yellow cuboid diamonds from placers in the north-eastern Siberian Platform
}

\author{
Rudolf I. MASHKOVTSEV ${ }^{1, *}$, Marianna I. RAKHMANOVA², Dmitry A. ZEDGENIZOV1,3 \\ ${ }^{1}$ Sobolev Institute of Geology and Mineralogy Siberian Branch Russian Academy of Sciences, 3 Koptyug ave., Novosibirsk 630090, \\ Russia; email: rim@igm.nsc.ru \\ ${ }^{2}$ Nikolaev Institute of Inorganic Chemistry Siberian Branch Russian Academy of Sciences, 3 Lavrentyev str., Novosibirsk 630090, \\ Russia \\ ${ }^{3}$ Zavaritsky Institute of Geology and Geochemistry Ural Branch Russian Academy of Sciences, 15 Vonsovskogo str., Ekaterinburg, \\ 620016, Russia \\ * Corresponding author
}

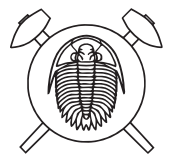

A series of yellow cuboid diamonds from alluvial placers in the north-eastern Siberian platform have been examined with Fourier-transform infrared (FTIR) absorption spectroscopy, photoluminescence (PL) and electron paramagnetic resonance (EPR). All crystals having characteristic FTIR spectra with predominantly $\mathrm{C}$ and A centres belong to mixed type IaA/Ib with small total nitrogen content (up to $330 \mathrm{ppm}$ ). PL is characterized by many bands with two bands related to the $\mathrm{NV}^{0}$ and $\mathrm{NV}^{-}$centres common to all the samples. The FTIR spectra are also characterized by deformation-induced 'amber' centers. Some of the yellow diamonds studied show new bands at 4272, 4548, and $5960 \mathrm{~cm}^{-1}$ instead of the bands at 4060 and $4170 \mathrm{~cm}^{-1}$ common for 'amber' centres. An EPR study has revealed the presence of OK1 centres associated with titanium impurity. The plastic deformation of the studied diamonds is expressed as a 'tatami' strain pattern in the features of their internal structure.

Keywords: diamond, cuboid, defects, nitrogen, Siberian platform

Received: 22 June 2020; accepted: 22 June 2021; handling editor: R. Skála

\section{Introduction}

The Siberian Platform hosts more than one thousand known kimberlite pipes. Hundreds of kimberlite pipes have been discovered in the north-eastern region of the Siberian platform, most of them are non-diamondiferous or extremely poor in diamonds. However, nearly $70 \%$ of the diamond-bearing alluvial placers occur here (Grakhanov et al. 2007). The primary sources of the diamonds in these placers have not been discovered yet despite intense exploration. According to the mineralogical classification system of Orlov (1977), the alluvial placer diamonds may be divided into the following three groups: (1) typical octahedral-to-rounded diamonds of variety I; (2) yellow-orange or dark grey cuboids of varieties II and III; and (3) rounded dark crystals of variety V. Minerals of eclogitic parageneses with a high content of titanium compounds dominate the available data regarding the composition of mineral inclusions in diamonds from placers (Sobolev et al. 1999; Shatsky et al. 2014; 2015).

Cubic-shaped diamond crystals (cuboids), forming a continuous colour series from yellowish-green to yellow and orange, are assigned to variety II (Orlov 1977). Diamonds of this variety comprise approximately $7.5 \%$ of the population of diamonds from alluvial placers (Grakhanov et al. 2007) but are rarely be found in kimberlite pipes. Yellow cuboid diamonds attract the attention of many researchers because of their specific spectroscopic and isotopic characteristics (Nadolinny et al. 2009b; 2012; 2015; Hainschwang et al. 2012; 2013; Mineeva et al. 2013; Zudina et al. 2013; Titkov et al. 2015b; Zedgenizov et al. 2016; 2017; Reutsky et al. 2017; Smit et al. 2018; Vasilev et al. 2020). This study is part of continuing research on alluvial diamonds from the north-eastern Siberian platform. We provide a new dataset on structural defects in yellow cuboid diamonds as revealed by FTIR absorption spectroscopy, photoluminescence (PL) and electron paramagnetic resonance (EPR).

\section{Samples and experimental methods}

Eleven diamonds coloured from pale yellow to dark orange-brown were selected from a commercial diamond collection from alluvial placers in the north-eastern $\mathrm{Si}$ berian platform. The diamonds presented as transparent cuboid (i.e. nearly cubic shape) to subrounded crystals 2-3 mm in size (Fig. 1). Most of them are significantly resorbed and have a typical tetrahexahedroid morphology. All samples were cut and polished into thin plates to observe their internal structure and acquire the IR spectra from different growth zones. The birefringence 

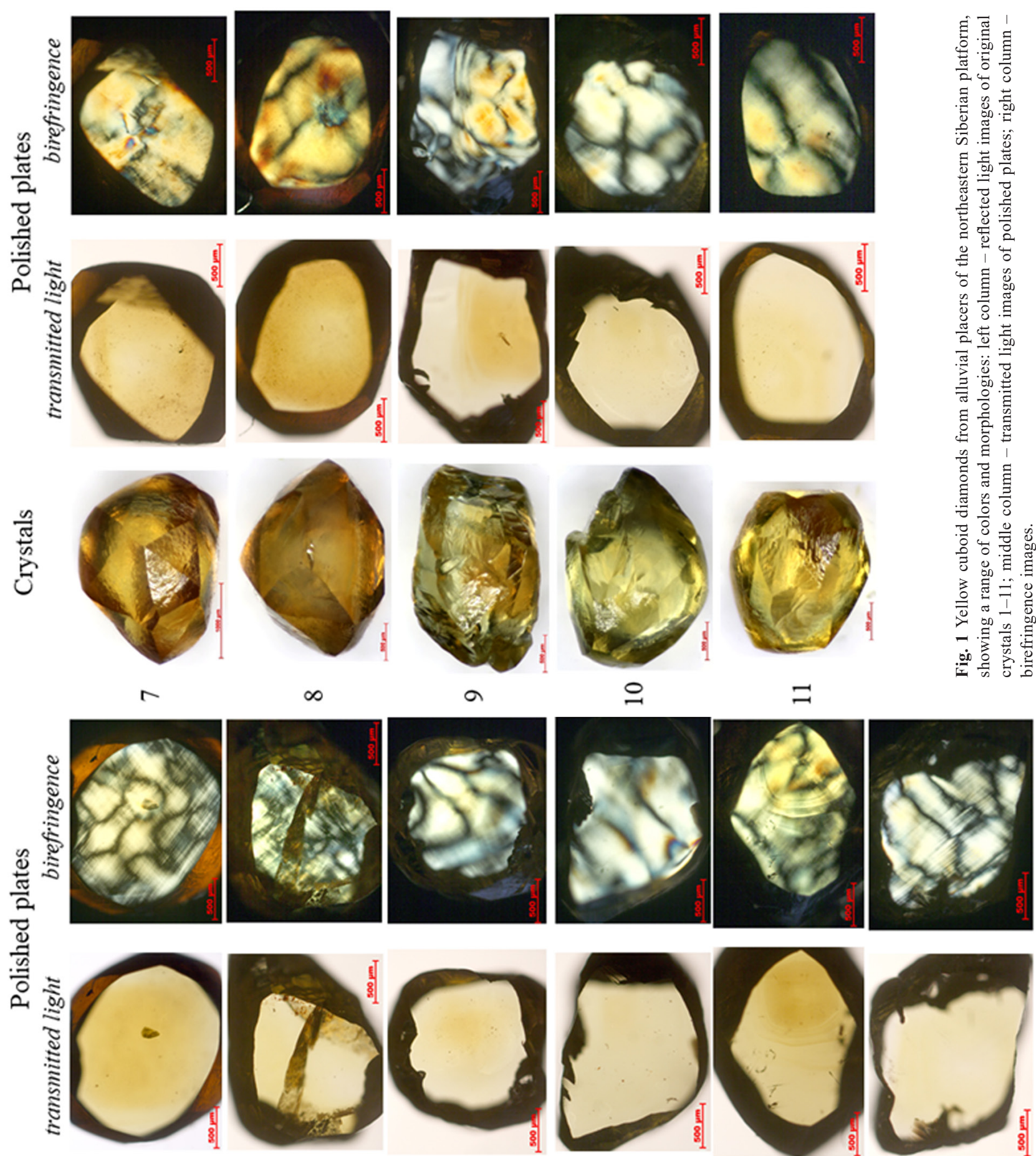

$$
\text { a }
$$
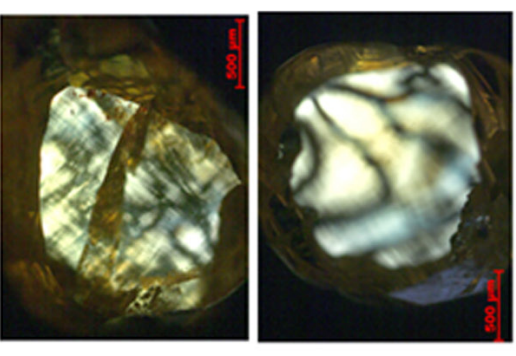

$$
\stackrel{ }{\circ}
$$

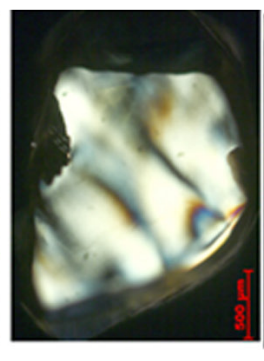

二
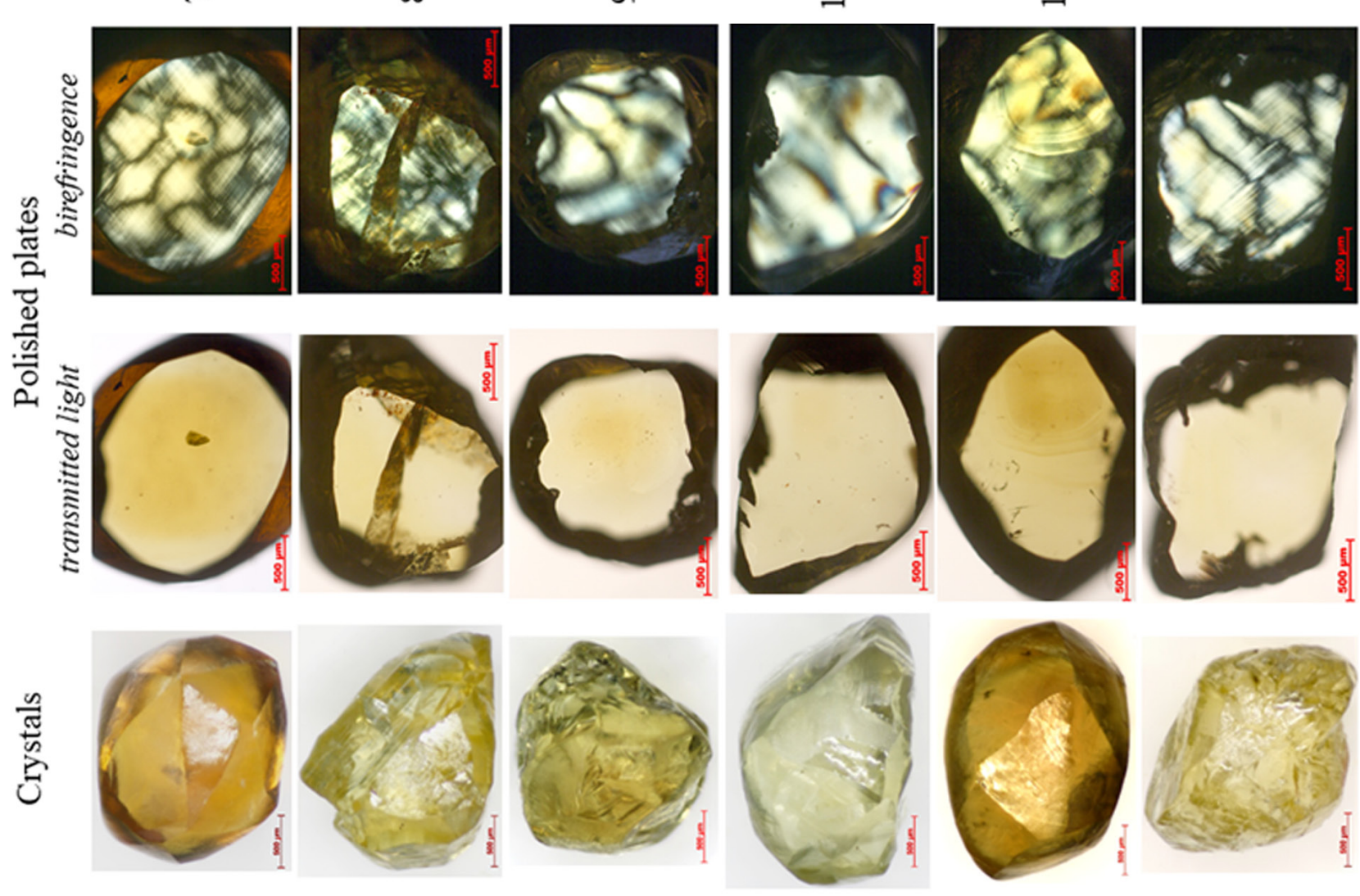

N

$m$

$\checkmark$

6 
patterns of the polished plates were observed using a Zeiss Axioskeop 40 microscope. The infrared spectra of the diamonds were recorded using a Bruker VERTEX 70 FTIR spectrometer equipped with a HYPERION 2000 microscope. Spectra were measured in a range of $7000-600 \mathrm{~cm}^{-1}$, with 32 scans at a resolution of $2 \mathrm{~cm}^{-1}$. The spectra were recorded using an aperture of $60 \times 60$ $\mu \mathrm{m}$. FTIR spectra were recorded at suitable points for all samples before polishing. The thin plates were then cut and the number of nitrogen centres has been estimated from the spectra recorded from different growth zones of each crystal. After the baseline subtraction and standard normalization to the intrinsic absorption of diamonds (12.8 $\mathrm{cm}^{-1}$ at $2030 \mathrm{~cm}^{-1}$, Zaitsev 2001), the concentrations of the major nitrogen defects $(\mathrm{C}$ - single-substitutional nitrogen atoms, $\mathrm{A}$ - adjacent-substitutional pair of nitrogen atoms, B - four nitrogen atoms surrounding a vacancy, and $\mathrm{X}$ - positively charged single-substitutional nitrogen, $\mathrm{N}^{+}$) were calculated by the decomposition of the one-phonon region of the IR spectra into individual components based on the ratios $\left[N_{\mathrm{A}}(\mathrm{ppm})=16.5 \times \alpha 1282\right.$ $\left(\mathrm{cm}^{-1}\right) ; N_{\mathrm{B}}(\mathrm{ppm})=79.4 \times \alpha 1282\left(\mathrm{~cm}^{-1}\right) ; N_{\mathrm{C}}(\mathrm{ppm})=$ $25 \times \alpha 1130\left(\mathrm{~cm}^{-1}\right)$; and $\left.N_{\mathrm{X}}=5.5 \times \alpha 1332\left(\mathrm{~cm}^{-1}\right)\right]$ proposed by Kiflawi et al. (1994), Boyd et al. (1995), Lawson et al. (1998), and Zaitsev (2001).

Photoluminescence (PL) spectra in the range 400-850 $\mathrm{nm}$ at $80 \mathrm{~K}$ were acquired under the $313 \mathrm{~nm}$ line (filtered through UFS-2 glass) of a mercury DRT-230 lamp and diode laser with $\lambda=532 \mathrm{~nm}$ for the range $540-850 \mathrm{~nm}$ using a DFS-24 spectrometer equipped with a doublegrating monochromator with 1200 lines/mm gratings and an FEU 79 photomultiplier for signal detection. The spectral resolution varied from 0.3 to $0.6 \mathrm{~nm}$ depending on the luminescence intensity and half-width of the zerophonon lines (ZPL). No correction for the response of the recording system was made.

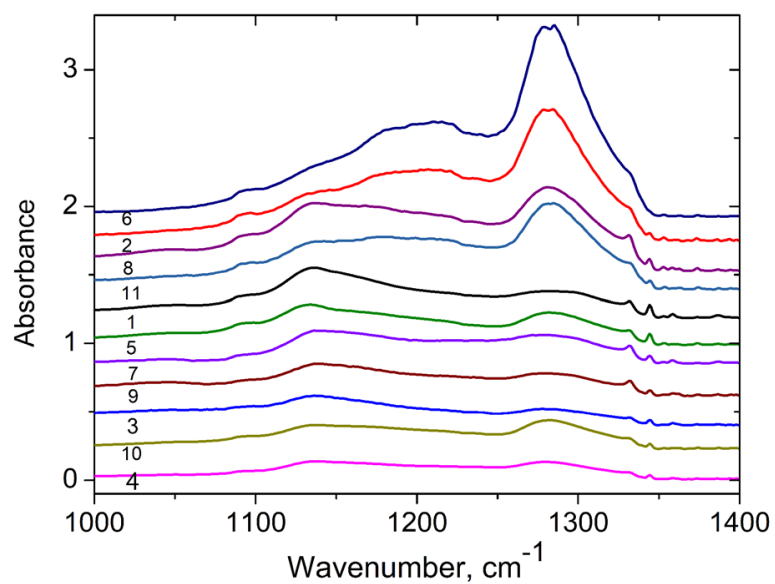

Fig. 2 The one-phonon region of FTIR spectra for raw diamonds. The numbers of the samples are marked.
EPR spectra were measured at room temperature on a Radiopan SE/X 2543 spectrometer with a built-in NMR magnetometer. The sample was fastened on a custombuilt goniometer allowing two-axis rotation of the crystal in the cavity. The output EPR signal was digitized with a custom 16-bits analogue-digital converter interfaced with a PC. The $100 \mathrm{kHz}$ modulation amplitude was selected so that narrow EPR lines without significant broadening were detected. The microwave power was reduced to 0.6 $\mathrm{mW}$ when the spectra of defect centres were collected because of EPR signal saturation.

\section{Results}

\subsection{FTIR data}

The FTIR spectra of the original diamond crystals are displayed in Fig. 2. The diamonds studied contain predominantly C (single nitrogen atom; Kiflawi et al. 1994) and A (pair of neighbouring nitrogen atoms; Davies 1976) centres and may be assigned to mixed Type $\mathrm{IaA} / \mathrm{Ib}$. Total nitrogen content is low from 46 to $330 \mathrm{ppm}$ (Tab. 1). For diamonds with a combination of nitrogen defects, the content in each form is determined by computer minimization of the component spectra to the experimental spectrum. The diamonds studied can be divided into two groups. The first group contains only two samples ( 2 and 6 ) which show IR spectra that may be fitted using mostly A and C defects with the possible addition of a minor amount of $\mathrm{B}$ (a group of four nitrogen atoms replacing carbon around the vacancy; Zaitsev 2001) and X centres (Fig. 3). These samples have higher total nitrogen content.

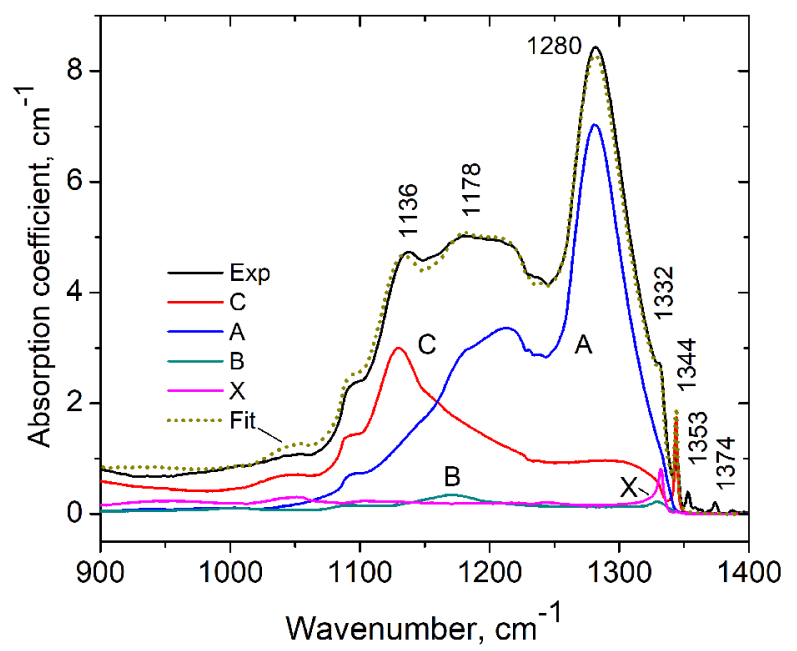

Fig. 3 Curve fitting analysis of the one-phonon region of FTIR spectrum for sample 2 (experimental black curve). The decomposition reveals the presence of the A (blue), C (red), B (dark cyan)) and X (magenta) nitrogen defects. The sum of those components is the fitting curve (short dot dark yellow line). 
Tab. 1 Infrared (FTIR), electron paramagnetic resonance (EPR) and photoluminescence (PL) characteristics of yellow cuboid diamonds from alluvial placers of the northeastern Siberian platform

\begin{tabular}{|c|c|c|c|c|c|c|c|c|c|c|c|c|}
\hline \multirow[b]{2}{*}{ No } & \multirow[b]{2}{*}{ Color } & & \multicolumn{6}{|c|}{ FTIR data } & \multicolumn{2}{|c|}{ EPR } & \multicolumn{2}{|r|}{ PL centers } \\
\hline & & & $\mathrm{C}, \mathrm{ppm}$ & A, ppm & $\mathrm{X}, \mathrm{ppm}$ & $\mathrm{Y}$ & $\begin{array}{c}\alpha, \\
3107 \mathrm{~cm}^{-1}\end{array}$ & $\begin{array}{c}\text { Amber center, } \\
v\left(\mathrm{~cm}^{-1}\right)\end{array}$ & $\begin{array}{l}\mathrm{P} 1, \\
\text { ppm }\end{array}$ & OK1 & $\lambda_{\mathrm{exc}}=313 \mathrm{~nm}$ & $\lambda_{\mathrm{exc}}=532 \mathrm{~nm}$ \\
\hline \multirow{2}{*}{1} & \multirow{2}{*}{$\mathrm{y}-\mathrm{or}$} & $\mathrm{C}$ & 112 & 17 & 6 & \multirow[t]{2}{*}{+} & 0.07 & - & \multirow[t]{2}{*}{100} & \multirow[t]{2}{*}{-} & \multirow[t]{2}{*}{-} & \multirow{2}{*}{$\begin{array}{c}\mathrm{NV}^{0}, 586.5,601.0,612.0,615.0 \\
635.7, \mathrm{NV}^{-}\end{array}$} \\
\hline & & R1R2 & 3672 & 1313 & 33 & & 0.040 & 3454,4240 & & & & \\
\hline \multirow{2}{*}{2} & \multirow{2}{*}{$\mathrm{y}$-green } & $\mathrm{C}$ & 51 & 172 & 3 & - & 0.5 & 4072 & \multirow[t]{2}{*}{90} & \multirow[t]{2}{*}{+} & $\mathrm{S} 1$ & \multirow[t]{2}{*}{$\mathrm{NV}^{0}, 612.4,635.7, \mathrm{NV}^{-}$} \\
\hline & & R1R2 & 7079 & 115142 & 55 & & 0.60 .5 & 3460,4250 & & & & \\
\hline \multirow{2}{*}{3} & \multirow[b]{2}{*}{ grey-y } & $\mathrm{C}$ & 50 & 26 & 2 & + & 0.1 & 4110,4240 & \multirow[t]{2}{*}{70} & \multirow[t]{2}{*}{+} & S1 (H3?) & \multirow[t]{2}{*}{$\mathrm{NV}^{0}, 612.4,635.7, \mathrm{NV}^{-}$} \\
\hline & & R1R2 & 3429 & 2216 & 11 & & 0.070 .04 & 4110,4240 & & & & \\
\hline \multirow{2}{*}{4} & \multirow{2}{*}{ grey } & $\mathrm{C}$ & 28 & 18 & 1 & + & 0.03 & $3460,4072,4244$ & \multirow[t]{2}{*}{60} & \multirow[t]{2}{*}{+} & $\mathrm{N} 3, \mathrm{~S} 1$ & \multirow[t]{2}{*}{$\mathrm{NV}^{0}, 612.4, \mathrm{NV}^{-}$} \\
\hline & & R1R2 & 1326 & 2823 & 11 & & 0.060 & 4066,4232 & & & & \\
\hline \multirow[t]{2}{*}{5} & \multirow{2}{*}{ or-br } & $\mathrm{C}$ & 59 & 24 & 2 & + & 0.06 & $4272,4548,5969$ & \multirow[t]{2}{*}{90} & \multirow[t]{2}{*}{-} & - & $\begin{array}{c}555.0, \mathrm{NV}^{0}, 579.5,586.5,612.4 \\
\mathrm{NV}^{-}\end{array}$ \\
\hline & & R1R2 & 5462 & 2327 & 22 & & 00.02 & $4272,4550,5960$ & & & & \\
\hline 6 & $\mathrm{y}$ & $\mathrm{C}$ & 47 & 172 & 5 & - & 0.9 & $3460,4072,4234$ & 65 & + & $\mathrm{N} 3, \mathrm{~S} 1$ & $\begin{array}{c}555.0, \mathrm{NV}^{0}, 579.5,586.5,612.4 \\
\mathrm{NV}^{-}\end{array}$ \\
\hline & & R1R2 & 5043 & 160299 & 45 & & 0.90 .7 & $3460,4072,4234$ & & & & \\
\hline 7 & $\mathrm{hr}-\mathrm{red}$ & $\mathrm{C}$ & 62 & 29 & 5 & + & 0 & 4280 broad & 90 & + & Broad band & $\begin{array}{l}\mathrm{NV}^{0}, 582.8,586.5,590.5,593.0, \\
596.0,599.0,601.0,603.5,607.5\end{array}$ \\
\hline 1 & or-red & R1R2 & 5762 & 2922 & 4 & & 0 & 4230 broad & & & & $\begin{array}{c}612.0,615.0,617.0,619.5,635.7 \\
\mathrm{NV}^{-}\end{array}$ \\
\hline 8 & hr red & $\mathrm{C}$ & 91 & 84 & 8 & + & 0.6 & 3465,4254 & 120 & - & - & $\mathrm{NV}^{0}, 612.4, \mathrm{NV}^{-}$ \\
\hline 8 & br-red & R1R2 & 9199 & 2847 & 8 & & 0.20 .4 & 3465,4260 & & & & \\
\hline & & $\mathrm{C}$ & 52 & 23 & 6 & + & 0.1 & 3480,4260 & 75 & + & N3 & $\mathrm{NV}^{0}, 612.4, \mathrm{NV}^{-}$ \\
\hline 9 & grey-red & R1R2 & 1771 & 2627 & 15 & + & 0.030 .1 & 4065,4250 & & & & \\
\hline 10 & & $\mathrm{C}$ & 25 & 50 & 2 & + & 0.2 & $3465,4115,4250$ & 65 & + & $\mathrm{S} 1$ & $\mathrm{NV}^{0}, 612.4, \mathrm{NV}^{-}$ \\
\hline 10 & y-green & R1R2 & 4334 & 5152 & 22 & & 0.20 .2 & 3465,4240 & & & & \\
\hline 11 & & $\mathrm{C}$ & 45 & 36 & 2 & + & 0.1 & - & 80 & + & $\mathrm{S} 1$ & 555.0, $\mathrm{NV}^{0}, 612.4,635.7, \mathrm{NV}^{-}$ \\
\hline 11 & $\mathrm{y}$-or & R1R2 & 4930 & 3727 & 22 & & 0.10 & - & & & & \\
\hline
\end{tabular}

The second group is characterized by low total nitrogen content wherein the number of $\mathrm{C}$ defects is more than or comparable to the number of A defects. Besides $\mathrm{A}$ and $\mathrm{C}$ centres they also show the presence of specific $\mathrm{X}$ and $\mathrm{Y}$ centres (Figs. 4 and 5). The $\mathrm{X}$ centre with a sharp
IR peak at $1332 \mathrm{~cm}^{-1}$ has been related to a positively charged single substitutional nitrogen atom (Lawson et al. 1998). The Y centre with the main band at 1140-1150 $\mathrm{cm}^{-1}$ has been described in Type $\mathrm{Ib}$ and $\mathrm{IaA} / \mathrm{Ib}$ of diamonds (Hainschwang et al. 2012; Titkov et al. 2015b;
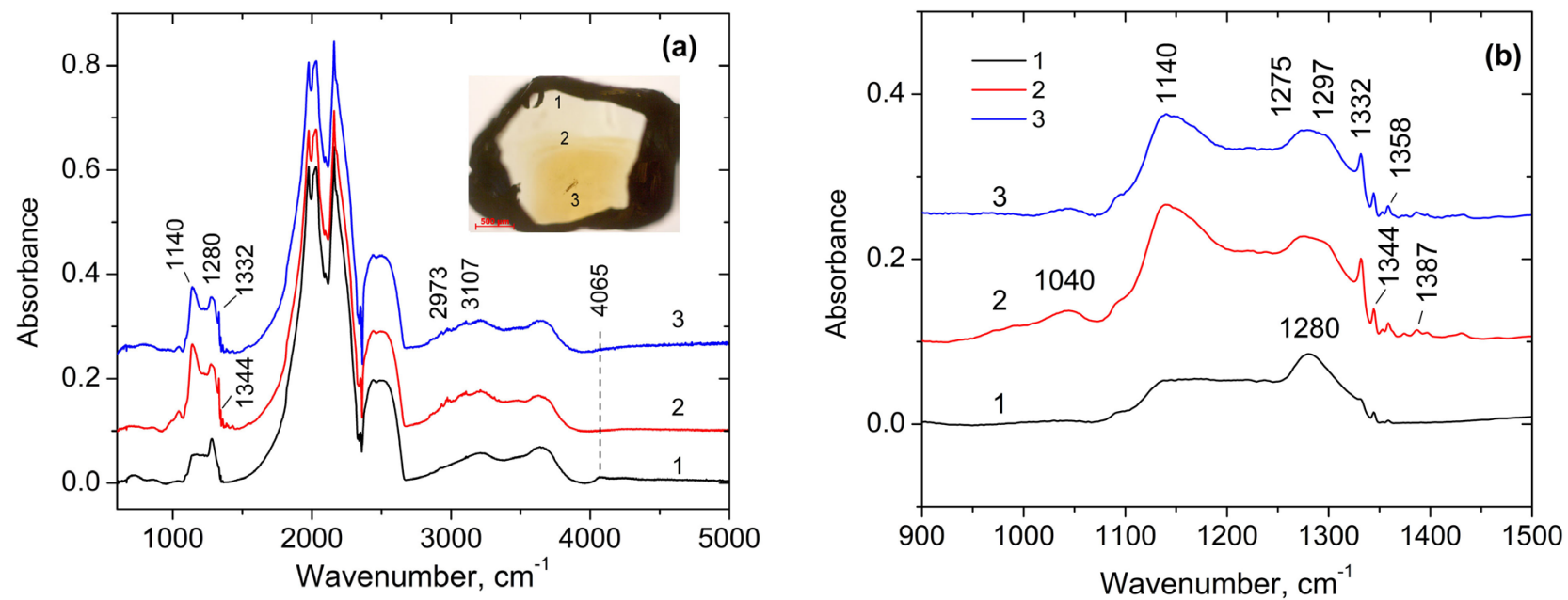

Fig. 4 FTIR spectra of different growth zones in diamond 9. (a) Full spectra with the location of zones shown on transmitted light image (upper corner). (b) The more detailed spectra in the one-phonon spectral region. 


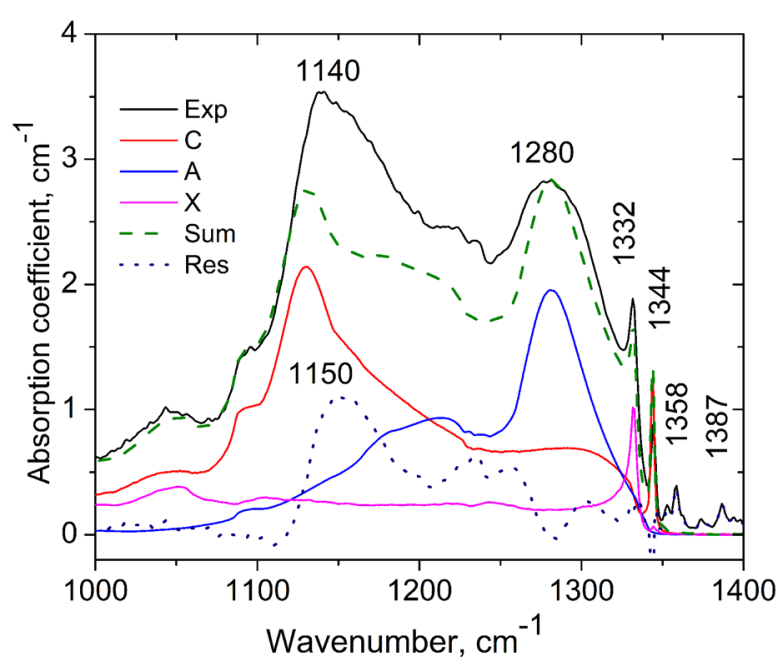

Fig. 5 Result of the decomposition of the IR spectrum (one-phonon region) of the central zone for sample 7. Exp - experimental spectrum (black line), C (red), A (blue), X (magenta) nitrogen defects. Sum of the $\mathrm{C}, \mathrm{A}$, and $\mathrm{X}$ components (olive dash line) and Res (residual - dot navy curve).

Zedgenizov et al. 2016). A broadened C centre absorption indicates the $\mathrm{Y}$ centre shifted to a position between 1135 and $1140 \mathrm{~cm}^{-1}$, instead of the standard position at $1130 \mathrm{~cm}^{-1}$. Additional peaks at 1353,1358,1363, 1374 and $1387 \mathrm{~cm}^{-1}$ also appear to be associated with a $\mathrm{Y}$ centre (Hainschwang et al. 2012; Titkov et al. 2015b). Recently, the peak intensity at $1358 \mathrm{~cm}^{-1}$ and the peak at $1332 \mathrm{~cm}^{-1}$ were correlated and hence the latter peak is involved in the full spectrum of $\mathrm{Y}$ centre (Reutsky et al. 2017). A minor amount of $Y$ centres might be present in the diamonds of the first group instead of B centres as suggested (see Fig. 3).

The peak at $3107 \mathrm{~cm}^{-1}$ related to $\mathrm{C}-\mathrm{H}$ vibrations is detected in most of the samples studied. Based on recent experimental data and theoretical calculations it was shown that the $\mathrm{VN}_{3} \mathrm{H}$ structural unit is the most appropriate candidate for the $3107 \mathrm{~cm}^{-1}$ centre (Goss et al. 2014). The diamonds show low-intensity absorption at 3107 $\mathrm{cm}^{-1}$ (Tab. 1) and rare additional weak H-related features (peaks at 2854, 2870, 2932, 2973, 3144, 3309, 3343, $3394 \mathrm{~cm}^{-1}$ ), in contrast to some samples with intense Y centre where the hydrogen-related features comprised a large number of intense, sharp peaks (Hainschwang et al. 2012).

Another specific feature of yellow cuboid diamonds is absorption bands in the near-infrared region (between 3900 and $6000 \mathrm{~cm}^{-1}$ ) (Tab. 1), associated with so-called 'amber' centres (DuPreez 1965; Massi et al. 2005). These bands in four studied samples are shown in Fig. 6. The 'amber' centres have been detected in many natural diamonds with global origins and are typically assigned to plastic deformation (DuPreez 1965; Massi et al. 2005; Fedorova et al. 2013; Hainschwang et al. 2013; Titkov et al. 2015b). Massi et al. (2005) have indicated that there are at least four different configurations of 'amber' centres, and all of them have been found in crystals showing the lamellae of plastic deformation and nitrogen in A-form. The spectra of yellow cuboid diamonds appear to be made up of a superposition of independent bands at $4067,4098,4113,4137,4170$, and possibly $4676 \mathrm{~cm}^{-1}$ that cannot be assigned to any groups proposed earlier (Massi et al. 2005). Usually, for such diamonds, the bands at about 4060 and $4170 \mathrm{~cm}^{-1}$ are observed at room temperature (Fedorova et al. 2013; Massi et al. 2005; Titkov et al. 2015b). Titkov et al. (2015b) have observed additional bands at 3460 and $4244 \mathrm{~cm}^{-1}$. We also observed the bands at 3468 and $4234 \mathrm{~cm}^{-1}$ in the yellow cuboid diamonds. New bands at 4272, 4548, and $5960 \mathrm{~cm}^{-1}$ are also observed in sample 5 (Fig. 5).

\subsection{EPR data}

The paramagnetic centre P1 related to the substitutional nitrogen atoms is observed in EPR spectra of all the yellow cuboid diamonds studied in this work. The number of paramagnetic nitrogen defects may be evaluated according to the method described by van Wyk et al. (1997). Peak-to-peak line widths changing from $0.8 \mathrm{G}$ in sample 4 to $1.2 \mathrm{G}$ in sample 8 correspond to $\mathrm{P} 1$ concentrations between 60 and $120 \mathrm{ppm}$ (van Wyk et al. 1997). The minimal and maximal concentrations of $\mathrm{C}$ centres determined from FTIR spectra generally corresponded to EPR measurements (Tab. 1). Each method has advantages. The IR beam penetrates through the entire thickness of the crystal or plate and measuring in one place necessarily includes other

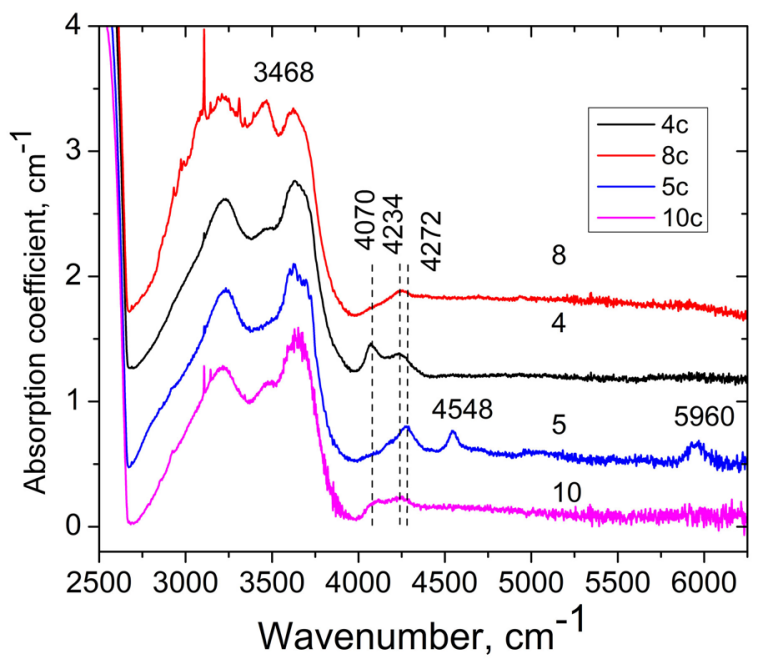

Fig. 6 Three-phonon spectral region of FTIR spectra for central zones of samples 4, 5, 8, and 10. Sharp bands of hydrogen-related defects between 2900 and $3400 \mathrm{~cm}^{-1}$ are observable. The bands of amber centers of different types are marked. 


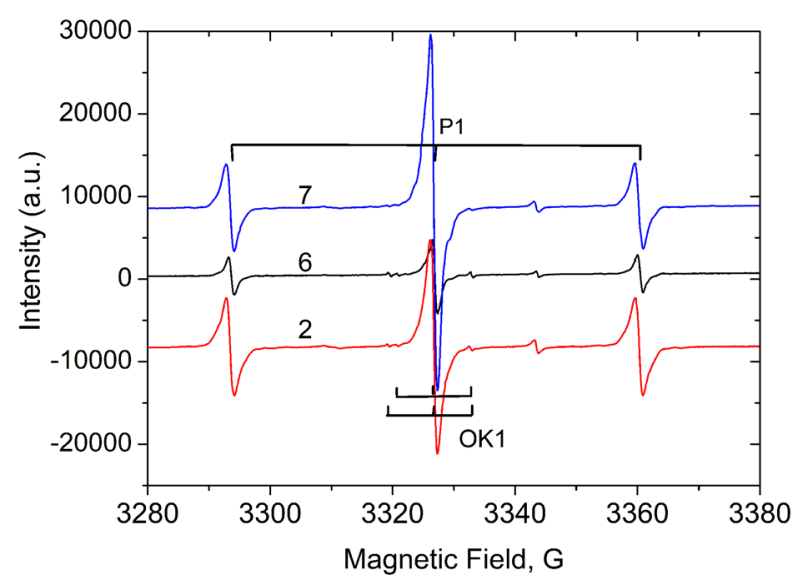

Fig. 7 X-band EPR spectrum taken with the applied magnetic field along [100] direction for the samples 2, 6, 7 .

zones. In the samples with unknown IR absorption attributed to $\mathrm{Y}$ centres, the simulation of the experimental FTIR spectrum is uncertain (see Fig. 4). EPR can only measure the concentration of the whole crystal, which is estimated roughly by the method of van Wyk et al. (1997). Another possible method of EPR evaluation of $\mathrm{P} 1$ content is by comparison with the standard sample. Comparison gave a lower concentration versus FTIRbased measurement of the $\mathrm{C}$ defects (Mineeva et al. 2013; Titkov et al. 2015a).

In most samples, the OK1 centre is also fixed by EPR with concentrations of about two orders less than those of the P1 centres (for example, in sample 6 the OK 1 content is about $1 \mathrm{ppm}$ ) (Fig. 7). The OK1 centre was first detected by Klingsporn et al. (1970). Based on electron-nuclear double resonance (ENDOR), the model of the chain $\mathrm{C}-\mathrm{N}-\mathrm{C}-\mathrm{O}-\mathrm{C}$ in the [110] direction was suggested for this centre (Newton and Baker 1989).

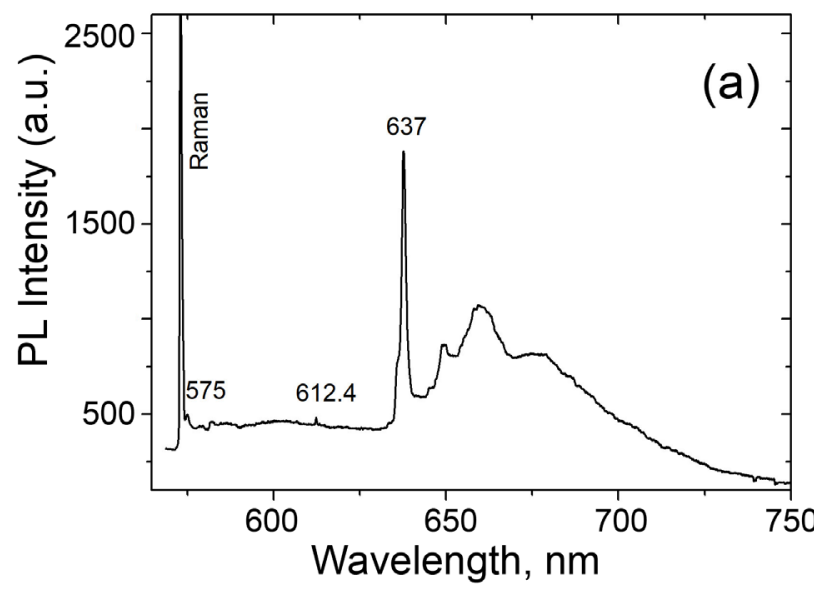

\subsection{Photoluminescence}

\subsection{1. $313 \mathrm{~nm}$ excited PL}

When excited at $313 \mathrm{~nm}$ the crystals had yellow or yellowish-green luminescence of different intensities. A zonal luminescence pattern was distinctly observable. In addition to the centre S1 (ZPLs at $503.4 \mathrm{~nm}$ and 510.7 $\mathrm{nm}$ ), the centre $\mathrm{H} 3$ (with an $\mathrm{N}-\mathrm{V}-\mathrm{N}$ structural model) was recorded nearby at $503.2 \mathrm{~nm}$. This proximity made it difficult to distinguish them due to their weak intensities. The $415 \mathrm{~nm}$ centre (N3 - three nitrogen atoms plus a vacancy, $\mathrm{N}_{3} \mathrm{~V}$ ) has been registered in three diamonds at lower intensities. In sample 7, a weak S1 centre was observed on a broad background, and three samples did not show any luminescence at this excitation.

\subsection{2. $532 \mathrm{~nm}$ excited PL}

When excited at $532 \mathrm{~nm}$, the crystals had a bright orange luminescence. This colour of luminescence is caused by the presence of either neutral $\left(\mathrm{NV}^{0}\right)$ or negatively charged $\left(\mathrm{NV}^{-}\right)$nitrogen-vacancy centres with ZPL at 575 and 637 nm, respectively (Fig. 8a, b). The $612.4 \mathrm{~nm}$ centre (the 612.5 or $613 \mathrm{~nm}$ centre in some studies) was observed in nine samples with the highest intensity of the ZPL at $612.4 \mathrm{~nm}$ in sample 6 . The vibrational sidebands are formed by interactions with 38 and $78 \mathrm{meV}$ phonons close to a quasi-local vibration of a vacancy. A peak at $612 \mathrm{~nm}$ has been observed in untreated plastically deformed brown and pink diamonds (Hainschwang et al. 2006; Titkov et al. 2008; Tretiakova 2009; Gaillou et al. 2010; Yuryeva et al. 2020). The 613-nm centre has also been observed in the grains of polycrystalline samples, from colourless to those dyed various shades of grey and yellow (Yang et al. 2012). We did not find evidence of a

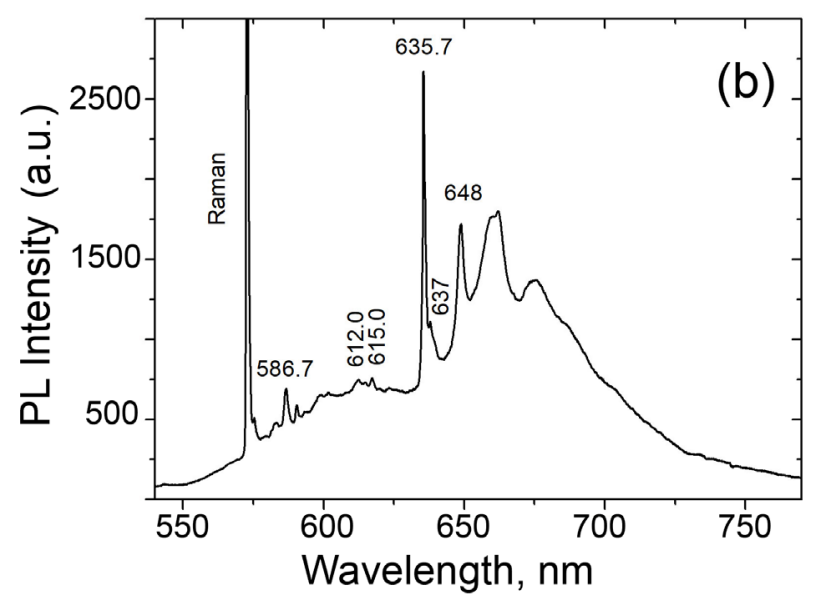

Fig. 8 Photoluminescence spectrum of diamonds (a) 2 and (b) 7 (excitation $\lambda=532 \mathrm{~nm}$ ). Specific lines are marked. 
relationship between the intensity of the $613 \mathrm{~nm}$ centre and the total nitrogen concentration. It can, therefore, only be assumed that there are nitrogen atoms and vacancies in its structure. The $613 \mathrm{~nm}$ centre is quite stable at high temperatures and can be completely annealed only at $2000^{\circ} \mathrm{C}$ and $6.5 \mathrm{GPa}$ (Tretiakova 2009; Yuryeva et al. 2015).

The centre with ZPL at $635.7 \mathrm{~nm}$ and local vibration at about $37 \mathrm{meV}$ was observed in the spectra of five of the diamonds studied. This centre has previously been detected in many yellow cuboid diamonds (Zudina et al. 2013; Zedgenizov et al. 2016). The correlation between the $635.7 \mathrm{~nm}$ luminescence system and the N3 centre detected by EPR has recently been demonstrated by Nadolinny et al. (2015). However, although we observed the $635.7 \mathrm{~nm}$ system in yellow cuboid diamonds we did not detect the N3 centre with EPR. A set of other centres was also observed, i.e. in sample 7 the highest peak was seen at $635.7 \mathrm{~nm}$ (Fig. 8b, Tab. 1). For sample 7 some Ni-related lines were observed at 596.0, 599.0 and 603.5 $\mathrm{nm}$ in PL spectra (Yelisseyev and Kanda 2007; Tretiakova 2009; Dobrinets et al. 2013).

\section{Discussion}

Yellow cuboid diamonds from the alluvial placers of the north-eastern Siberian platform are of particular scientific interest. Previously described characteristics of such diamonds i.e., primary cuboid morphology, light carbon isotope composition, and low aggregated nitrogen (Type Ib has a specific yellow colouration), suggest an unusual primary source (Zedgenizov et al. 2016). FTIR studies of similar diamonds have revealed a specific set of C, A, X and Y centres (Titkov et al. 2015b). In nine of the diamonds studied we detected the same set of centres. Only two samples (2 and 6) have negligible amounts of $\mathrm{Y}$ centres present. The presence of $\mathrm{C}$ centres and absence of B centres are usually attributed either to relatively cool conditions during the storage of diamonds in the mantle or short mantle residence time before the eruption. In contrast, high-temperature annealing results in the formation of aggregated A centres. Some crystals show a concentration of $\mathrm{C}$ centres and their nitrogen aggregation state is higher in the core than that at the periphery. Vasilev et al. (2020) has recently explained this contradiction as syn-growth incorporation of nitrogen directly as paired atoms (A centre) as it has previously been shown to be the case for synthetic crystals (Palyanov et al. 1997; Yelisseyev et al. 1996).

Recently it has been found that in natural diamonds from eclogitic xenoliths the detection of paramagnetic $\mathrm{OK} 1$ and N3 centres correlated with the abundance of titanium compounds (Nadolinny et al. 2009b, 2012 and
2015). The samples with observed OK1 and N3 centres have low total nitrogen concentration of about $10 \mathrm{ppm}$ because the titanium is the nitrogen getter (Nadolinny et al. 2012). The OK1 centres have only been observed in diamonds of cubic habits (Nadolinny et al. 2012). Furthermore, N3 centres were observed in diamond crystals synthesized in systems with a high titanium content (Nadolinny et al. 2009a). Experiments with HTHP annealing at $7 \mathrm{GPa}$ and $2470 \mathrm{~K}$ have demonstrated that in some crystals the EPR spectrum of the N3 centre eventually disappeared and the EPR signal from the OK1 centre appeared (Nadolinny et al. 2015). The optical counterpart of the OK1 and N3 centres are the S1 centre (ZPLs at 503.4 and $510.7 \mathrm{~nm}$ ) and the $440.3 \mathrm{~nm}$ system, respectively (Zaitsev 2001; Nadolinny et al. 2009a, b, 2012). In the diamonds studied the paramagnetic N3 centre and PL with ZPL at $440.3 \mathrm{~nm}$ were not observed.

Comprehensive investigations using EPR and photoluminescence methods suggest that the N3 and OK1 centres can be modelled as a Ti atom in the substitutional position and a Ti atom in the structure of a double semivacancy with one neighbouring nitrogen atom, respectively (Nadolinny et al. 2009b, 2012, 2015). Previously, density functional theory (DFT) calculations for OK1 and N3 centers did not support models containing both oxygen and titanium impurities (Etmimi et al. 2010). However, a recent hybrid DFT analysis (Czelej et al. 2018) provided strong evidence that the neutral Ti-N and TiV-N complexes are indeed the experimentally observed N3 (titanium-nitrogen) and OK1 (titanium-vacancy-nitrogen) colour centres. It is well known that titanium is a nitrogen getter. Because of crystal growth in a titaniumcontaining medium, the titanium atoms can fit into the diamond structure as $\mathrm{TiN}$ or $\mathrm{TiCN}$ molecular units. Internal structure strains may be substantially reduced when large titanium atoms are forced out from their substitution sites into the double semi-vacancy position (an OK1 defect according to Nadolinny et al. 2009b, 2012).

It has been shown that cubic diamonds have a fibrous internal structure (Moore and Lang 1972; Lang 1974; Orlov et al. 1982; Sunagawa 1990; Ragozin et al. 2017). Cuboid diamonds with specific fibrous internal structures could have crystallized under high supersaturation (Sunagawa 1990). Growth under high supersaturation can induce plastic autodeformation (Punin 1981). The plastic deformation of the diamond samples in this work is revealed by the features of the internal structure (Fig. 1). These structures appear as a 'tatami' pattern (two crossed directions of strain lamination) in the birefringence patterns and electron backscatter diffraction (EBSD) images (Ragozin et al. 2017). The 'amber' centres observed in FTIR spectra (see Fig. 6) are also related to plastic deformation (Massi et al. 2005). Besides amber centres, Type $\mathrm{Ib}$ diamonds exhibit the nitrogen-vacancy defects $\left(\mathrm{NV}^{0}\right.$, 
NV) observed with PL (Hainschwang et al. 2013, Smit et al. 2018). The characteristic luminescence centre with ZPL at $635.7 \mathrm{~nm}$ was initially attributed to a positively charged vacancy (Charles et al. 2003) but further experimental study has not confirmed this attribution (Steeds et al. 2000). An EPR study of a series of natural cuboid diamonds showed that there could be both a titanium atom and a vacancy in the structure of defect responsible for the optical system at $635.7 \mathrm{~nm}$ (Nadolinny et al. 2015). The diamonds studied are also characterized by additional luminescence centres: N3, H3, S1, $\mathrm{NV}^{0}$ and $\mathrm{NV}^{-}$(Zaitsev 2001). This set of defects in diamonds has been suggested to form at the stage of post-growth deformation (Titkov et al. 2015b).

The current understanding of the NV centres has recently been discussed in reviews by Doherty et al. (2013) and Pezzagna et al. (2011). The NV centres are produced by the interaction of substituting $\mathrm{N}_{\mathrm{s}}$ and vacancies that are introduced through either irradiation or deformation (Collins 1982). The absence of radiation damage (green or brown spots) and induced GR1 centres $\left(\mathrm{V}^{0}\right)$ in the studied diamonds (Nasdala et al. 2013) support deformation as the origin of the vacancies. Plastic deformation forms dislocations in the lattice that may generate vacancies (Hull and Bacon 1984). In the PL spectra of natural untreated diamonds, the intensity of the $638 \mathrm{~nm}$ center is usually less than that of the $575 \mathrm{~nm}$ centre (Dobrinets et al. 2013). In contrast, the $638 \mathrm{~nm}$ centre $\left(\mathrm{NV}^{-}\right)$is stronger than the $575 \mathrm{~nm}\left(\mathrm{NV}^{0}\right)$ in PL spectra of the diamonds in this study (Fig. 8). A possible reason for this is that nitrogen $\mathrm{C}$ centres serve as donors. $\mathrm{NV}$ centres capture the extra electrons and become $\mathrm{NV}^{-}$centres while $\mathrm{C}$ centers transform to $\mathrm{N}^{+}$(X centres). NV defects have rather low-temperature stability and may anneal out completely at temperatures above $1500^{\circ} \mathrm{C}$ (Dobrinets et al. 2013).

\section{Conclusions}

FTIR spectroscopy data indicate that in yellow cuboid diamonds from the north-eastern Siberian platform the nitrogen is predominantly presented in $\mathrm{C}$ and $\mathrm{A}$ forms. The lack of nitrogen in B form testifies to the low temperature or short mantle residence time of the diamond genesis. The observed higher aggregation in the peripheral zones of some studied diamonds might be explained by syngrowth incorporation of nitrogen directly as paired atoms. EPR observation has revealed Ti-related OK1 defect in yellow cuboids which could result from the reduction of strains induced by plastic deformation. The formation of NV centres can also be explained by plastic deformation. These new spectroscopic data suggest a plastic deformation within yellow cuboid diamonds which could occur synchronously with their growth. Such cuboid diamonds are suggested to grow fast under high supersaturation. This follows from the manifestation of specific fibrous internal structures that can cause plastic auto-deformation.

Acknowledgements. We thank the Member of the Editorial Board Dr. R. Skála and two reviewers for their helpful work. The spectroscopic study was supported by the Russian science foundation (20-05-00338). Support of FTIR spectroscopic analyses from the Russian foundation for basic research (18-05-70064) is also appreciated. The study of morphology and sample preparation was a part of the state assignment project of IGM SB RAS.

\section{References}

Boyd SR, KifLawi I, Woods GS (1995) Infrared absorption by the $\mathrm{B}$ nitrogen aggregate in diamond. Philos Mag B72: 351-361

Charles SJ, Steeds JW, Butler JE, Evans DJF (2003) Optical centers introduced in boron-doped synthetic diamond by near-threshold electron irradiation. J Appl Phys 94: 3094-3100

Collins AT (1982) Colour centres in diamond. J Gemmol 18: $37-75$

Czelej K, Ćwieka K, ŚPiewak P, Jan Kurzydeowski K (2018). Titanium-related color centers in diamond: a density functional theory prediction. J Mater Chem C 6: $5261-5268$

DAVIES G (1976) The A nitrogen aggregate in diamond - its symmetry and possible structure. J Phys C: Solid State Phys 9: L537

DoBrinETS IA, VINS VG, ZAITSEV AM (2013) HPHT-treated diamonds: diamonds forever. Springer Series in Materials Science 181, Springer, Berlin, pp 1-257

Doherty MW, Manson NB, Neil B, Delaney P, Jelezko F, Wrachtrup J, Hollenberg LCL (2013) The nitrogenvacancy colour centre in diamond. Phys Rep 528: 1-45

DuPreEz L (1965) Electron paramagnetic resonance and optical investigations of defect centres in diamond. $\mathrm{PhD}$ Thesis, Univ of Witwatersrand, Johannesburg

Etmimi KM, Goss JP, Briddon PR, Gsiea AM (2010) A density functional theory study of models for the N3 and OK1 EPR centres in diamond. J Phys: Condens Matter 22: 385502

Fedorova EN, Logvinova AM, Mashkovtsev RI, Sobolev NV (2013) Internal structure and color of the natural plastically deformed diamonds from the Internatsionalnaya kimberlite pipe. In: PEARson DG et al. (eds) Proceedings of $10^{\text {th }}$ International Kimberlite Conference. Special Issue J Geol Soc India. Geol Soc India Vol.1, pp 323-333

Gaillou E, Post J, Bassim N, Zaitsev AM, Rose T, Fries M, Stroud RM, Steele A, Butler JE (2010) Spectroscopic and microscopic characterization of color lamel- 
lae in natural pink diamonds. Diamond Relat Mater 19: $1207-1220$

Goss JP, BRiddon PR, Hill V, Jones R, Rayson MJ (2014) Identification of the structure of the $3107 \mathrm{~cm}^{-1} \mathrm{H}$-related defect in diamond. J Phys: Condens Matter 26: 145801

Grakhanov SA, Shatalov VI, Shtyrov VA, Kychion VR, Suleimanov AM (2007). In: Dodin DA (ed) Diamond Placers of Russia. Akademicheskoe Izd. "Geo": Novosibirsk, Russia, pp 454 (In Russian)

Hainschwang T, Notari F, Fritsch E, Massi L (2006) Natural, untreated diamonds showing the A, B and C infrared absorptions ("ABC" diamonds) and the $\mathrm{H} 2$ absorption. Diam Relat Mater 15: 1555-1564

HainschWANG T, Fritsch E, NotaRi F, RondeAu B (2012) A new defect center in type $\mathrm{Ib}$ diamond inducing one phonon infrared absorption. Diamond Relat Mater 21: $120-126$

Hainschwang T, Fritsch E, Notari F, Rondeau B, KaTRUSHA A (2013) The origin of color in natural C center bearing diamonds. Diamond Relat Mater 39: 27-40

Hull D, BACon DJ (1984) Introduction to dislocations. Pergamon Press, Oxford, pp 1-257

Kiflawi I, Mayer AE, Spear PM, Van Wyk JA, Woods GS (1994) Infrared absorption by the single nitrogen and A defect centres in diamond. Philos Mag B69: 1141-1147

Klingsporn PE, Bell MD, Leivo WJ (1970) Analysis of an electron spin resonance spectrum in natural diamonds. J Appl Phys 41: 2977-2980

LANG AR (1974) Space-filling by branching columnar single-crystal growth: An example from crystallization of diamond. J Cryst Growth 23: 151-153

Lawson SC, Fisher D, Hunt DC, Newton ME (1998) On the existence of positively charged substitutional nitrogen in diamond. J Phys: Condens Matter 10: 6171-6180

Massi L, Fritsch E, Collins AT, Hainschwang T, Notari F (2005) The "amber centres" and their relation to the brown colour in diamond. Diamond Relat Mater 14: 1623-1629

Mineeva RM, Zudina NN, Titkov SV, Ryabchikov ID, SPERANSKY AV, Zudin NG (2013) EPR-spectroscopy of diamonds of cubic habit from the placers in the NorthEast of the Siberian platform: new type of nitrogen centers. Dokl Earth Sci 448: 243-247

MoORE M, LANG AR (1972) On the internal structure of natural diamonds of cubic habit. Philos Mag 26: 1313-1325

Nadolinny V, Yuryeva O, Chepurov A, Shatsky V (2009a) Titanium ions in the diamond structure: model and experimental evidence. Appl Magn Reson 36: 109-113

Nadolinny VA, Yuryeva OP, Shatsky VS, Stepanov AS, Golushko VV, Rakhmanova MI, Kupriyanov IN, Kalinin AA, Palyanov YN, Zedgenizov DA (2009b) New data on the nature of the EPR OK1 and N3 centers in diamond. Appl Magn Reson 36: 97-108
Nadolinny VA, Yuryeva OP, Rakhmanova MI, Shatsky VS, PaLyanov YN, KuPRIYANOV IN, Zedgenizov DA, RAGOZIN AL (2012) Distribution of OK1, N3 and NU1 defects in diamond crystals of different habits. Eur J Miner 24: 645-650

Nadolinny V, Palyanov Y, Yuryeva O, Zedgenizov D, RakHManova M, Kalinin A, KomarovskikH A (2015) The influence of HTHP treatment on the OK1 and N3 centers in natural diamond crystals. Phys Stat Solidi A212: 2474-2479

Nasdala L, Grambole D, Wildner M, Gigler AM, Hainschwang T, Zaitsev AM, Harris JW, Milledge J, Schulze DJ, Hofmeister W, Balmer WA (2013) Radio-colouration of diamond: a spectroscopic study. Contrib Mineral Petrol 165 (5): 843-861

Newton EM, BAKER JM (1989) ${ }^{14} \mathrm{~N}$ ENDOR of the OK1 centre in natural type Ib diamond. J Phys: Condens Matter 1: 10549-10561

OrLOV YL (1977) The Mineralogy of the Diamond. John Wiley, New York, pp 1-235

Orlov YL, Bulienkov NA, Martovitsky VP (1982) A study of the internal structure of variety III diamonds by X-ray section topography. Phys Chem Miner 8: 105-111

Palyanov YN, Khokhryakov AF, Borzdov YuM, Sokol AS, Gusev VA, Rylov GM, Sobolev NV (1997) Growth conditions and real structure of synthetic diamond crystals. Rus Geol Geophys 5: 882-906

Pezzagna S, Rogalla D, Wildanger D, Meijer J, Zaitsev A (2011) Creation and nature of optical centres in diamond for single-photon emission-overview and critical remarks. New J Phys 13: 035024

PunIN YO (1981) Crystal splitting. Zap Vsesojuz mineral Obšč 110(6): 666-686 (In Russian)

Ragozin A, Zedgenizov D, Kuper K, Kalinina V, ZEMnUKHov A (2017) The internal structure of yellow cuboid diamonds from alluvial placers of the northeastern Siberian platform. Crystals 7: 238-250

Reutsky VN, Shiryaev AA, Titkov SV, Wiedenbeck M, ZuDINA NN (2017) Evidence for large scale fractionation of carbon isotopes and of nitrogen impurity during crystallization of gem quality cubic diamonds from placers of North Yakutia. Geochem Inter 55: 988-999

Shatsky VS, Zedgenizov DA, Ragozin AL, Kalinina VV (2014) Carbon isotopes and nitrogen contents in placer diamonds from NE Siberian craton: implications for diamond origins. Eur J Mineral 26: 41-52

Shatsky VS, Zedgenizov DA, Ragozin AL, Kalinina VV (2015) Diamondiferous subcontinental lithospheric mantle of the northeastern Siberian craton: Evidence from mineral inclusions in alluvial diamonds. Gondwana Res 28: 106-120

Smit KV, D'Haenens-Johansson UFS, Howell D, Loudin LC, WANG W (2018) Deformation-related spectroscopic features in natural type Ib-IaA diamonds from Zimmi 
(West African craton). Mineral Petrol 112 (Suppl 1): S243-S257

Sobolev NV, Sobolev VN, Snyder GA, Yefimova ES, TAYLOR LA (1999) Significance of eclogitic and related parageneses of natural diamonds. Inter Geol Rev 41: $129-140$

Steeds JW, Charles SJ, Davies J, Griffin I (2000) Photoluminescence spectroscopy of TEM irradiated diamond. Diamond Related Mater 9: 397-403

SunAGaWA I (1990) Growth and morphology of diamond crystals under stable and metastable contitions. J Cryst Growth 99: 1156-1161

Titkov SV, Shigley JE, Breeding CM, Mineeva RM, Zudin NG, Sergeev AM (2008) Natural color purple diamonds from Siberia. Gems Gemol 44 (1): 56-64

Titkov SV, Mineeva RM, Zudina NN, Sergeev AM, Ryabchikov ID, Shiryaev AA, Speransky AV, ZhikhaREVA VP (2015a) The luminescent nature of orange coloration in natural diamonds: optical and EPR study. Phys Chem Miner 42: 131-141

Titkov SV, Shiryaev AA, Zudina NN, Zudin NG, SoloDOVA YP (2015b) Defects in cubic diamonds from the placers in the northeastern Siberian platform: results of IR microspectrometry. Russ Geol Geophys 56: 354-362

Tretiakova L (2009) Spectroscopic methods for the identification of natural yellow gem-quality diamonds. Eur J Mineral 21: 43-50

Van Wyk J, Ryenhardt EC, High GL, Kiflawi J (1997) The dependences of ESR line widths and spin-spin relaxation times of single nitrogen defects on the concentration of nitrogen defects in diamond. J Phys D Appl Phys 30: 1790-1793

Vasilev EA, Zedgenizov DA, KlepiKov IV (2020) The enigma of cuboid diamonds: the causes of inverse distribution of optical centers within the growth zones. J Geosci 65: 59-70
Yang Z, Liang R, Zeng X, Peng M (2012) A microscopy and FTIR and PL spectra study of polycrystalline diamonds from Mengyin kimberlite pipes. ISRN Spectroscopy, Art ID 871824

Yelisseyev AP, Kanda H (2007) Optical centers related to $3 \mathrm{~d}$ transition metals in diamond. New Diamond Front Carbon Technol 17: 127-178

Yelisseyev A, Nadolinny V, Feygelson B, Terentyev S, NosukHIN S (1996) Spatial distribution of impurity defects in synthetic diamonds obtained by the BARS technology. Diamond Relat Mater 5: 1113-1117

YuRYeVA OP, RaKHMANOVA MI, NADOLINNY VA, ZeDGENIzov DA, Shatsky VS, Kagi H, Komarovskikh AY (2015) The characteristic photoluminescence and EPR features of superdeep diamonds (São-Luis, Brazil). Phys Chem Miner 42: 707-722

YuRYeVA OP, RaKhMANOVA MI, Zedgenizov DA, KaLININA VV (2020) Spectroscopic evidence of the origin of brown and pink diamonds family from Internatsionalnaya kimberlite pipe (Siberian craton). Phys Chem Miner 47: 20

ZAITSEV AM (2001) Optical properties of diamond: a data handbook. Springer, Berlin, p 502

Zedgenizov DA, Kalinina VV, Reutsky VN, Yuryeva OP, RAKHMANOva MI (2016) Regular cuboid diamonds from placers on the northeastern Siberian platform. Lithos 265: 125-137

Zedgenizov D, Reutsky VN, WiedenBeck M (2017) The carbon and nitrogen isotope characteristics of type Ib-IaA cuboid diamonds from alluvial placers in the Northeastern Siberian platform. Minerals 7(10): 178

Zudina NN, Titkov SV, Sergeev AM, Zudin NG (2013) The features luminescence centers in cubic diamonds with different color from placers Northeast Siberian Platform. Proc Russian Mineral Soc 4: 57-72 